\title{
Chinese academics writing for publication: English teachers as text mediators
}

\author{
Na Lua \& Ken Hyland
}

\section{Chinese academics: publishing imperatives and obstacles}

The imperative for academics to publish in internationally indexed English language journals has made itself felt in almost all corners of the world and China is no exception. Chinese scholars increasingly find their career opportunities depend on their ability to publish in high profile English language journals indexed in the Web of Knowledge science citation index $(\mathrm{SCI})$.

China's contribution to the global output of published papers has, as a result, therefore grown massively in recent years. An analysis of the 3 million plus submissions to 4,200 journals received through the manuscript processing system ScholarOne between 2005 and 2010, for example, shows that submissions from China increased by $484 \%$ (Thomson Reuters, 2012). Over the last decade, in fact, China increased its world share of submission by $5.5 \%$, advancing it from $14^{\text {th }}$ to $5^{\text {th }}$ in world output (Hyland, 2015). Recent figures from SCImago (2014) show China just behind the US in submissions and it leads the number of papers in the engineering index. In 2014 alone, academics in China published some 263,500 SCI-indexed articles, accounting for $14.9 \%$ of the world total, up from less than 50,000 in 2001 (ISTIC, 2015).

These increases reflect the significant investment China is making in funding research and the fact that several universities in China are working to attain "world-class university" status, through a significant beefing up of their publication productivity. As a result, many universities are offering monetary rewards to encourage academics to publish in international journals, such that inducements of GBP 20,000 for acceptance in Science or Nature are not unknown (Shao \& Shen, 2011). These pressures have also led some researchers to engage in unethical practices, and cases of fraud, plagiarism and "ghost authoring" have been widely documented (e.g. Hvistendahl, 2013; Zhang, 2010). 
Despite China's emergence as a major player in international publishing, writing in English often poses considerable challenge to many Chinese authors. This means that it trails the traditional publishing nations in both acceptance and citation rates. So while acceptances for submissions from the U.S., Germany, Australia, UK and Canada remained at around $50 \%$ of submissions between 2005 and 2010, China's massive increase in submissions produced no appreciable increase in acceptance rates which remained at around 26\% (Thomson Reuters, 2012). Similarly, published papers by Chinese authors have attracted fewer citations than those from traditional publication nations (Fu, Frietsch \& Tagscherer, 2013) and remain below world averages in citation counts (ISTIC, 2015) due to the low visibility of journals in which they often publish (Fu et al, 2013).

There are several possible reasons why submitted manuscripts from China fail to become published papers and receive fewer citations. While the unfamiliarity of publishing practices and lack of institutional support are likely to play a big role, the challenge presented by academic writing in English is obviously a key obstacle. Ehara \& Takahashi (2007), for example, found that language problems were a major reason for rejecting Chinese submissions to a leading international medical journal while this often encourages Chinese scientists to submit their papers to low impact SCI-indexed journals (Fu et al, 2013). As a result of these imperatives and obstacles, Chinese scientists often turn to those around them for help.

\section{Literacy brokers and text mediators}

The term "literacy brokers" was coined by Lillis and Curry (2010, p.88) to refer to "all the different kinds of direct intervention by different people, other than named authors, in the production of texts". They have also been referred to as translators, correctors, revisers, local editors, language professionals, language service providers, authors' editors (Burrough-Boenisch, 2003), proofreaders (Harwood, Austin \& Macaulay, 2009), article shapers (Burrough-Boenisch, 2003; Li \& Flowerdew, 2007), and convenience editors (Willey \& Tanimoto, 2012, 2013). While not wishing to add to this plethora of terms, we prefer "text mediators" as it describes a range of possible activities without the negative connotations of a 
commercial, strictly corporate relationship implied by "broker". While we understand Lillis and Curry's desire to refer to the "academic capital" gained from the work, this metaphor fails to capture the collaborative and typically collegial nature of our teacher-academics dyads. Indeed, it overlooks the ethical dimensions of the relationship, altogether, particularly the publishing credit which might be given to the mediator.

Drawing from the notion of "mediated authorship" (Prior, 1998, p.159), we call the English teachers who have worked on scientific research article manuscripts mediators. By mediators we highlight the role of university English teachers in seeking to work with authors to negotiate a safe passage for their papers through the review process, making direct textual interventions by way of corrections, changes or suggestions in texts for publication.

While interviews with editors and studies of reviewers' comments tend to find no undue attention to language in editorial decisions (e.g. Belcher, 2007; Coniam, 2012), critical comments on language, style or rhetorical conventions are frequently included in reviews (Mungra \& Webber, 2010; Mur Dueñas, 2012). Often reviewers lack a metalanguage to discuss rhetorical problems and tend to blame the writer's poor English (e.g. Kerans, 2001) while some editors insist on having submissions vetted by native English speakers (NESs) at the author's expense. Such admonishments, however, presuppose that native English speakers are locally accessible and willing to help, although this is not always the case in many Chinese cities (Li \& Flowerdew, 2007). More seriously, it assumes that editors are qualified automatically by their nativeness in English to edit academic papers.

\section{Non-native English speakers and non-specialists as mediators}

Fortunately, both manuscript editors and authors in the hard sciences have begun to realize the problematic nature of this native/non-native dichotomy which unfairly privileges NESs over NNESs as text mediators. The Society of English-Native-Speaking Editors (SENSE) in The Netherlands, for example, despite its name, admitted NNES editors as associate members at its outset in the 1990s and has recently voted against the distinguishing between these categories while the more recently inaugurated Mediterranean Editors and Translators (MET) also includes both NES and NNES members. Similarly, Willey and Tanimoto (2012, 2013), after initially 
excluding NNES editors from their study of convenience editorial services for Japanese healthcare professionals, have more recently admitted that "scientific editing is also done by English as an Additional Language (EAL) language professionals" (2015, p. 66).

While we acknowledge that differences exist between NESs and NNESs due to their first language background and prior experiences, there are difficulties in framing linguistic disadvantage in terms of a native/non-native divide (Davies, 2003; Hyland, 2015, 2016). NESs, in fact, may lack the necessary familiarity with the rhetorical conventions of the author's field and so fail to "merit author's trust and payment" (Benfield \& Feak, 2006, p.1730). The features of academic writing can cause difficulties for both native and non-native English-speakers, and the former are often less "academically bilingual" than many EAL scholars (Hyland, 2015, 2016). Thus, even in Anglophone countries like the UK, author-recruited editors can be both NESs and NNESs (Harwood et al, 2009).

Similar to the native/non-native divide, the specialist/non-specialist dichotomy also looms large in the debate of who might be the more competent text mediators for EAL scholars. While Harwood et al (2009) find their sample of UK editors divided in their willingness to mediate texts beyond their own disciplines, Lillis \& Curry (2010), comparing the textual interventions recommended by NES senior specialists and those by a NES non-specialist English teacher, conclude that those by the former were far more effective in enhancing the chance of publication for EAL scholars. Similarly, Willey \& Tanimoto $(2012,2013,2015)$ found that NES editors with a health-care background were more effective than NES English teachers when editing a medical abstract by a Japanese author, concluding that NES English teachers need to learn the styles and terminology of the EAL writers they help, involve authors in the editing process and acquire the ability to communicate with those authors. The issue that language professionals need to consult with authors when editing texts for publication has also been made with reference to China (Li \& Flowerdew, 2007).

The point we wish to make here, however, is that the specialist/non-specialist dichotomy implies that non-specialists are inevitably disadvantaged when mediating manuscripts by EAL authors. EAL scientists, however, have been soliciting advice from non-specialist teachers for years, helping them to turn their manuscripts into "crisp English" (Könner, 1994, p44). Over 20 
years ago, Gosden (1992), for example, discussed a course helping Japanese academics writing for publication and Sionis (1995) reported shepherding rejected manuscripts by French scientists into publication. In Europe such language service providers, many with only qualifications in language, are extremely well organized and have their own associations. SENSE has over 350 members, for example, and MET has an annual conference and occasional publications (e.g. Matarese, 2013). Professional authors' editors have also staked a claim for their work in the academic literature (e.g. Kerans, 2001; Shashok, 2014).

In China professional writing support companies have also mushroomed in the past few years, although they continue to be viewed with suspicion (e.g. Cargill, O'Connor \& Li, 2012; Li \& Flowerdew, 2007). One reason for this is the dubious ethical reputation of some services. A recent investigation by Science, for example, discovered numerous Chinese professional editing services selling such attractive options as an authorial slot on a paper written by other scientists, authorship on ghost written manuscripts already accepted by an ISI journal, and papers ghost written from faked data or data provided by the customer (Hvistendahl, 2013). For a fee of up to US\$26,300 for first authorship, a sum far exceeding the annual salary of most full professors in China, desperate academics can get their names into prestigious journals by writing no more than a check.

These problematic practices give such companies a dubious reputation and so they are often treated with caution. Many scientists thus prefer to ask locally available, personally known and more trusted English teachers for assistance with their manuscripts. In contrast to Lillis and Curry's (2010) findings in European settings that local text brokers, particularly language professionals, played only a minor role, we found these teachers are often pivotal to the rapidly increasing publishing success of Chinese academics on the world stage. We believe that the unsung work of these teachers should be made more widely known and in this paper explore eight cases to show something of this growing phenomenon. Here, then, we describe a different publishing reality to that which seems to function in the west and sketch the benefits and challenges of this practice for participants. Importantly, this study points to a valuable but underdeveloped resource for Chinese academics en route to international publication. If properly nurtured by institutional support, this resource may help more Chinese authors to turn 
their submissions into published papers in quality journals.

\section{Theoretical framework}

In this study, we draw from the theory of structuration (Giddens, 1984) and are particularly interested in understanding agency and how power relations are interpersonally negotiated between Chinese scientist authors and their local text mediators. In this theory, agency and structure, rather than forming an opposing dichotomy, constitute an interdependent and complementary duality. While power relations are inherent in both agency and structure, they involve different power categories (Giddens, 1984; Larder, 2006). Although the lop-sided structural power may manifest itself more conspicuously, it is agentive power (both individual and intersubjective) which sustains the very existence of any social system (Giddens, 1984).

Agency, to the intentional capability of people to do things in ways which differ from those offered by the structural properties of a context, involves agentive power, or the ability to effect changes in this way (Giddens, 1984). Since the doing of anything cannot be dissociated from its social context, the exploration of agency and related power dynamics must be situated in social practice. Accordingly, our inquiry into Chinese scientists writing in English for international publication is anchored in the social practices of that activity, thus linking individual writing activities with the context in which they occur, including both structural constraints and contextual resources (See Layder, 2006).

While a social practice view of academic literacy inevitably embraces rich power dynamics, our approach differs from that of the New Literacy Studies scholars who see power as a consequence of formal relationships defined by context, so that "literacy brokers occupy a powerful position straddling boundaries and peripheries between communities and groupings" (Lillis \& Curry, 2010: 88). Instead, we highlight the individual agentive power exercised by Chinese scientist authors and their text mediators, and the interpersonal power dynamics between them. Agency and agentive power are dynamic. Under certain conditions, individual and interpersonal agency may transform into more powerful collective agency (Archer, 1995). In this study, we intend to show how agency together with its related interpersonal power dynamics work and its potential to transform relatively powerless and marginalized groups on the periphery of academic publishing into collective agency. 
To examine the dynamics of agency and agentive power in the social practices of local English teachers mediating texts by scientists in China, the study seeks to address the following research questions:

1. How are ties established and developed between Chinese English teachers and authors?

2. What are the main obstacles affecting English teachers mediating Chinese authors' texts? How do they exert agency to overcome these problems?

3. What actions do English teachers take in mediating scientific manuscripts and to what extent are they successful?

4. What factors affect the cooperation between local English teachers and scientist authors?

\section{Participants and methods}

Chinese tertiary institutes offering degree programs were divided into three tiers according to their involvement and success in international publishing: national universities, provincial universities, and regional ones. Our study examines text mediation practices among English teachers and researchers at one university from each tier, a national research-oriented university (NU), a provincial university (PU), and a regional university (RU), to determine whether practices differ across these contexts. Participants were recruited by posting messages on the bulletin boards of English departments in each university inviting English teachers with experience in providing writing support to scientists to join the study. Responses were patchy and we excluded several respondents who were unable to provide feedback from authors or access to previous drafts so that ultimately two teachers at NU (T1-T2) and six at PU (T3-T8) were interviewed. Although no English teacher from RU responded to the participant recruiting message, an internationally published author (A4) who once asked an English teaching colleague at RU to translate a paper was willing to share his experiences.

All the participants recruited were local Chinese teachers, reflecting the fact that very few NES teachers are hired in Chinese universities and those that are work under restrictions which prevent them in engaging in additional work. One participant was the first author of this paper, a veteran English teacher who has edited manuscripts for Chinese scientists over a decade. Here we follow Canagarajah (2012) who argues that, in language research, the researcher him/herself 
should be valued as "a rich repository of experiences and perspectives" (p. 260). She wrote a detailed recount as a text mediator in response to questions posed by the second author in lieu of the interview. Table 1 gives information on the participants.

Table 1: Participants in the study

\begin{tabular}{|c|c|c|c|c|c|c|}
\hline $\begin{array}{l}\text { Participant } \\
\text { Teachers }\end{array}$ & Affiliation & Gender & Teaching experience & Age & $\begin{array}{l}\text { English } \\
\text { scripts } \\
\text { edited }\end{array}$ & $\begin{array}{l}\text { Chinese } \\
\text { scripts } \\
\text { translated }\end{array}$ \\
\hline $\mathrm{T} 1$ & NU & male & $\begin{array}{l}\text { Academic writing to } \\
\text { doctoral student }\end{array}$ & $30-39$ & $>60$ & 1 \\
\hline $\mathrm{T} 2$ & NU & female & $\begin{array}{l}\text { Academic writing to } \\
\text { doctoral student }\end{array}$ & $40-49$ & 1 & 0 \\
\hline $\begin{array}{l}\mathrm{T} 3 \\
\text { (first } \\
\text { author) }\end{array}$ & $\mathrm{PU}$ & female & $\begin{array}{l}\text { Medical \& general } \\
\text { English to } \\
\text { undergraduates }\end{array}$ & $40-49$ & 30 & 0 \\
\hline $\mathrm{T} 4$ & $\mathrm{PU}$ & male & $\begin{array}{l}\text { Academic writing to } \\
\text { graduate students }\end{array}$ & $40-49$ & 4 & 0 \\
\hline T5 & $\mathrm{PU}$ & female & $\begin{array}{l}\text { General English to } \\
\text { graduates }\end{array}$ & $40-49$ & 5 & 0 \\
\hline T6 & PU & female & $\begin{array}{l}\text { General English to } \\
\text { undergraduates }\end{array}$ & $30-30$ & 3 & 3 \\
\hline $\mathrm{T} 7$ & PU & male & $\begin{array}{l}\text { General English to } \\
\text { graduate } \\
\text { students }\end{array}$ & $40-49$ & 4 & 0 \\
\hline $\mathrm{T} 8$ & $\mathrm{PU}$ & female & $\begin{array}{l}\text { General English to } \\
\text { graduate } \\
\text { students }\end{array}$ & $30-39$ & 5 & 0 \\
\hline Authors & Affiliation & & & & $\begin{array}{l}\text { Papers } \\
\text { published } \\
\text { in English } \\
\end{array}$ & $\begin{array}{l}\text { Scripts } \\
\text { mediated } \\
\text { by teachers }\end{array}$ \\
\hline A1 & PU & male & & $50-59$ & 23 & 19 \\
\hline $\mathrm{A} 2$ & NU & female & & $20-29$ & 1 & 1 \\
\hline A3 & NU & male & & $20-29$ & 1 & 1 \\
\hline A4 & RU & male & & $40-49$ & 3 & 1 \\
\hline
\end{tabular}

Semi-structured interviews were conducted with all the English teachers (see schedule in Appendix 1) and authors in Chinese using a parallel set of questions. The interviews lasted about an hour with $\mathrm{A} 1$ and $\mathrm{A} 2$ being interviewed a second time to better understand the complexities of the text amendments on their manuscripts. Most interviews were carried out face-to-face and audiotaped while one teacher (T8) was interviewed online via the synchronous 
messaging service QQ. As noted, the first author responded to a similar set of questions in more detail in a written recount. Additional text data, including drafts, published articles, and the correspondence between authors and editors were also collected to complement and triangulate the interview data. Follow-up inquiries were made via QQ whenever necessary. Informed consent was obtained from all participants and interpretations checked with them for accuracy.

Recorded interviews were transcribed, translated into English, and entered into MAXQDA, a qualitative data analysis software, for coding together with records, including online interview, follow-up inquiries, and the first author's recount. The data from English teachers underwent a two-cycle procedure of open coding and axial coding as described in Saldaña (2009). In the first cycle, data were read line by line and assigned to broad categories. For example, "communication" was applied to the following data extract because the English teacher mentioned the advantages of mediating face-to-face with the author:

I think I can deal with it with the author's assistance. When my wife asked me to edit her doctoral classmates' paper, I said to her: "You'd better let him come when I edit. If I make mistakes alone, the paper may be rejected right away." (T7)

The second cycle of coding grouped these categories into themes based on the research questions and arising from the interview responses themselves: 1) establishing text mediation ties, 2) challenges of providing writing support, 3) strategies to overcome difficulties, 4) effectiveness of text mediation, and 5) attitudes to mediation. The texts were coded by both authors to gain familiarity with the data, and the themes were repeatedly refined over several weeks. Both authors also coded the qualitative data but here the categories were arrived at independently and then agreed by discussion rather than conducting a conventional reliability analysis using the same categories. Both processes yielded high rater agreement. The mediator's text interventions were also coded (Appendix 2), drawing on previous studies of revision (e.g. Gosden, 1995) and writing support (Lillis \& Curry, 2010; Willey \& Tanimoto, 2012), but modified to include the scale of revisions. We coded revisions below clause level as minor, those between clause and sentence as meso and those above the sentence as major. Sentence combination and splitting were counted as meso editing. Finer coding categories of 
addition, deletion, substitution/rewriting, reordering and reorganization were also used when necessary. Texts were double coded by both authors with an agreement of $95 \%$. We judged the success of mediation by whether it was included in the published version.

\section{Question 1: Ties, relationships and experiences in mediating practices}

We found complex relationships between the local English teachers and the authors, usually initiated by agency on the author's part. While the small scale of the study limits generalizations, our convenience sampling and inclusion of teachers at national and provincial universities suggests that these mediating activities are probably not atypical more widely across China.

At PU, T3 had been mediating manuscripts for 12 years, working with authors in four different disciplines from four universities. In particular she enjoyed a good relationship with A1, a senior professor of physiology and former vice president of PU, editing 19 of the 23 English manuscripts his research group had published since 2004. This connection also encouraged A1 to transform individual agency into collective agency by initiating a centre through which English teachers formally provide a mediating service to support the publishing efforts of doctoral students. Personal relationships are often the basis for the intersubjective agency of forging and sustaining ties with academics for mediators, so T6, for example, translated three articles by her husband, a professor at another university, and edited another three manuscripts by his graduate students. Similarly, the first manuscript T7 mediated was authored by his wife, an associate professor at another national university before he went on to edit papers by colleagues at PU.

T1, another English teacher working at NU teaching academic writing to science doctoral students, began exerting agency in mediating texts since 2006 following his experience with a writing centre at a US university while an undergraduate. He eventually started charging a fee for editing academic manuscripts and built a client base through personal recommendations following successful publications. He has now mediated over 60 papers in energy research, computer science, material science, mechanical engineering and law. In contrast, T2 was much less involved in manuscript editing. Despite the advantages of having a UK PhD in applied linguistics and experience as an academic writing teacher, her heavy teaching load and pressures 
to publish her own research left her little time to mediating the texts of others. As a result, she funneled interested scientists to T1 and had only edited one paper herself.

Mediating ties at RU, a somewhat remote regional medical university, were also initiated by author agency when under-pressure junior academics anxious to secure whatever mediating help they could find. A4, a doctor at the affiliated hospital, for example, approached an English teaching colleague to translate his first paper into English for submission to an international journal. Unfortunately, his submission was rejected with reviewers making critical comments on the language. He privately blamed the teacher's translation for this rejection and consequently turned to commercial translation services.

These kinds of fortuitously initiated mediation activities are repeated across our data and confirmed by the anecdotes of our colleagues and students. Far from being the unusual practice that Cargill et al (2012) suggest, many local English teachers are exercising their agency across China and are involved in close and sustained relationships shaping scientists' manuscripts for publication.

\section{Question 2: Challenges for local English teachers and their agency in overcoming difficulties}

Like the NES English teachers in Willey \& Tanimoto's (2015) study, all local language professionals in this study, with the exception of $\mathrm{T} 8$, emphasized that unfamiliarity with disciplinary knowledge and rhetorical conventions were among their main concerns in editing manuscripts. They pointed out that this was unfamiliarity with the content was exacerbated by the fact that the manuscripts were littered with non-standard uses which made the authors' intensions difficult to follow. A2 confessed that she often had difficulty expressing herself and so just used the "textual borrowing" strategy reported in Flowerdew \& Li (2007) of re-using published sentences as frames for her own content. When she could not find a suitable structure from published papers for her intended meaning, she simply made do with roughly appropriate expressions. Similarly, T7 found that the explanations his clients provided when discussing their scripts in Chinese frequently deviated from what they had tried to convey in English.

What is in the text isn't at all what the author wants to express...this just 
confuses me-as an English teacher without any of their disciplinary knowledge.

All our teachers except T8 demonstrated their agency as mediators by discussing texts with the authors and working closely with them to shape their desired meanings. Since most were in the same institution, or in the same city, face-to-face meetings were common. T4, for example, reported that as an experienced author himself, he considered it unprofessional to mediate a manuscript without consulting the author:

I have never edited a manuscript without discussing changes with the author and wouldn't do that. Manuscripts contain a lot of new disciplinary knowledge which is alien to me. So I might introduce new errors if I didn't have the author's advice. I might reverse what the author intends to say or juxtapose concepts which should be separated.

All the other teachers, except T8, also met with authors face-to-face during the text mediation process whenever possible. $\mathrm{T} 1$ and $\mathrm{T} 3$, the most experienced mediators, often conferenced with authors a number of times, sometimes for several hours, for a single paper, especially during their early years of article mediation. Throughout these conferences, they sought to understand the author's intentions and establish the connections among concepts. They concurred that the author's presence greatly reduced their problem of insufficient disciplinary knowledge. In T1's words:

Regardless of which discipline the author belongs to, I always try my best to imagine what he or she is doing in the paper. I think I can more or less understand the major concepts and their connections when I have the author's explanation. I learnt science subjects in high school and as an undergraduate and so for me the disciplinary knowledge is not as intimidating as it might be.

Where distance made face-to-face conferences impossible, mediators exercised their agency by establishing a similar connection with their authors through online chat. Thus, both T1 and T3, communicated with them synchronously via QQ. In the past year, they have mediated 10 and 4 manuscripts respectively in this way and found it indispensable in 
understanding and rhetorically addressing authors' meanings. The importance these text mediators attached to communicating with authors is echoed in the literature (e.g. Kerans 2001). Willey and Tanimoto $(2012,2013,2015)$, for example, show that even editing short article abstracts may require NES mediators to make frequent contact with the author and argue that the involvement of authors in English teachers' editorial process is essential.

T8 was the only mediator who did not contact her authors while editing. She regarded such conferencing as too time-consuming and preferred to edit alone on a hard copy, only confirming her work with authors during post-editing meetings.

\section{Question 3: The effectiveness of teacher mediation}

While authors sometimes have firm ideas about what constitutes "native-like" expression, the success of teachers' efforts to mediate papers is ultimately judged by their acceptance by journal reviewers and editors. Overall, their agency has had considerable success in gaining publication in international ISI journals, although the learning curve for teachers can be steep. T3, for example, recounted occasions where reviewers criticized the language of papers she had first edited when helping Al's graduate students with their manuscripts, once requesting the authors to consult a NES, a remark she was very ashamed of:

I was devastated when I read the comment. I felt I was an impostor... I had misled the authors and wasn't qualified to help them with their writing.

However, A1 strategically exercised agency to solidify his text mediation tie with T3, reassuring her that she had pulled them one step closer to their publication goal since her editing had taken their manuscripts past the initial editorial screening and into review. To reward A1's confidence in her, she worked more meticulously, carefully scrutinizing the early papers several times, either alone or with the author. After several rounds of revision and repeated editing by T3, all the papers written by Al's graduate students, some of whom had very limited English proficiency, appeared in high quality SCI journals.

Gradually, T3's agentive power grew as a result of both experience and her active learning from the academic writing literature. Reviews of the manuscripts she had edited improved and she became a confident and accomplished mediator of research papers, invited to polish 
manuscripts by authors in several disciplines. A1 was particularly appreciative of T3's mediation, her commitment and willingness to learn from experience and the writing literature. When my first English article was published, in a local journal, I became more confident about her work. My second article in English, my first in an overseas journal, really boosted my trust in her. She is a keen learner, learning all the time...working together I've seen that she has been really committed without caring about rewards. English teachers need to have her spirit to develop into good advisors.

Emboldened by her success and growing familiarity with the rhetorical practices of her authors' fields, $\mathrm{T} 3$ began to extend her agency in her relationship with authors by making more extensive revisions to the papers she mediated, reorganizing the presentation of their content. One paper she mediated was by her former student, A2. A2's first paper in English had been edited by two commercial editing services, at considerable expense, before receiving a "revise and resubmit" decision from a journal, with the reviewers stating that she had failed to foreground the novelty of her findings sufficiently. Following a conference with the author, T3 was able to rectify this by restructuring the discussion section and the paper was accepted with minor revisions.

T3 initiated significant changes in this text. While the opening and closing paragraphs were only lightly edited, the middle was radically rewritten. Most changes at meso and major levels appeared in the published version, suggesting the success of T3's work. The following is an example (text slightly modified for anonymity)

Example 1 (words in bold added or relocated)

Fsg3, first named ABC, mediates mitochondrial fusion and maintains mitochondrial morphology and function (reshuffled from the $3^{\text {rd }}$ paragraph). Mitochondria have mostly been suggested to be related to atherosclerosis in three mechanisms (added). Firstly, they are the major site of SOR generation, which causes the oxidation of DLD and cellular oxidative stress, contributing to the pathogenesis of atherosclerosis (reshuffled and revised). Secondly, in vivo and in vitro studies indicate 
that-mitochondrial cholesterol transport is considered to be a crucial hinge to controlling macrophage cholesterol efflux, which is the initial step of the regression and stabilization of atherosclerotic lesions. Mitochondria are the major site of SOR generation, which causes the exidation of $\mathrm{DLD}$ and cellular oxidative stress, contributing to the pathegenesis of athereselerosis. (reshuffled forward).

This example, taken from the opening of the second paragraph, shows one of T3's major revisions to foreground the author's topic, Fsg3. Drawing on her knowledge of the research on move structures in the discussion section, T3 reordered the initial sentence to the current position, although only after fierce opposition by A2. The second sentence was added at her suggestion following a long consultation with A2, who then commented:

I suddenly found my argument being transformed. We're evaluating previous literature here rather than just listing them!

A2 then accepted all T3's suggested revisions, exclaiming at the end of the conference:

This is exactly what I wanted to say! This is exactly what I wanted to say but just didn't know how.

The paper was accepted by a prestigious indexed journal with only minor revisions, allowing A2 to qualify her for doctoral defense. She attributed this success to T3's mediation and confided to A3, her former classmate:

I was so grateful to her. She helped a lame dog over a stile.

T1, the other experienced manuscript editor in this study, shared many similar experiences in enacting agency to help authors to win a "respectful reading" (Shashok, 2001, p. 116) for manuscripts which had been rejected without review due to language problems. Like T3, he also edited each paper several times, both prior to submission and in response to reviewers' comments. In many cases, his mediation has also moved beyond surface forms to negotiate revisions of rhetorical structure with the authors.

Sometimes I suggest that authors should revise their abstract or introduction quite drastically. So if I see the way they have organized the introduction is 
problematic, or find logical gaps in a literature review, then I ask them to tell me what they are trying to say. After I get a general idea, I am in a better position to comment on it. This obviously touches on content, but I have probably given these kinds of comments in about $40 \%$ of the papers I have edited, particularly those by novice writers.

Our analyses of his drafts also reveal how he initiated important changes in reorganizing the paper to better express interpretations with supporting arguments. The following is the abstract of an article edited by $\mathrm{T} 1$.

Example 2 (words in bold added or relocated)

Current methods for $\mathbf{X}$ diagnosis of The grounding grid is very important for a power system, and a $X$ of the grounding grid using direct current DC or MC are limited in accuracy and cannot be used to identify the locations of the Xs. will bring huge loss. Therefore it is necessary to diagnose the $X$ of a grounding grid though an effective method. At present, the nodal potential or electromagnetic methods are generally used to diagnose the $X$ of grounding grids according to the time domain characteristic. (Rewriting) In this study a new method of the $\mathrm{X}$ diagnosis for substation grounding grids is proposed using a square-wave-is put forward. Firstly, aA frequency model of the grounding system is constructed by analyzing the frequency characteristics of the soil and the grounding conductors; into which two different frequency square-wave sources are injected. Then By analyzing and comparing the corresponding information of the surface potentials of the output signals has been aequired. Lastly by analyzing the corresponding information of these different frequencies, and comparing the surface potentials along with the frequency, the Xs of the grounding grid can be diagnosed and the $\mathrm{X}$ can be located. (combining of two sentences) Our method is verified by Ssoftware simulation, the laboratory scale model experiments and the field experiments-are made into this method and it's proved to be effective and feasible. (rewriting) 
Here T1 made both meso and minor revisions. When working alone without consulting the author, he made only a few minor revisions and gave three comments. Engaging with the author, he was able to delete redundant information and reconstruct logical relationships among concepts. The revisions made by $\mathrm{T} 1$ were included almost verbatim in the published article.

The successful experiences of $\mathrm{T} 1$ and $\mathrm{T} 3$ in exercising their agentive power to mediate these rhetorically complex and academically demanding texts corroborate Kerans' (2001) observation that, when conferencing with the author, the influence of language professionals can extend far beyond language into content. To borrow from the taxonomy of Harwood, Austin \& Macaulay (2012), if their role is that of a "cleaner" when working alone, they are empowered by experience to take the more critical roles of "leveler" by reducing disadvantages to EAL authors and "mediator" by being the bridge between authors and critical gatekeepers. Although language professionals like the English teachers in this study cannot effect many changes by relying on their own limited disciplinary knowledge, "powerful meanings and effective ways of communicating meaning" emerge through dialogue between them and authors (Kyburz, 2004, p. 518). The sum of individual agentive power is greater than its parts.

Burrough-Boenisch (2013) observes that mediating EAL-authored manuscripts involves several layers of editing, from copy-editing to substantial revision and translation and, because of the complexity of the task, language professionals sometimes fail to satisfy the exacting expectations of reviewers. Occasionally, papers $\mathrm{T} 1$ had edited received critical comments on language from reviewers, and such setbacks spurred him to renewed efforts as he took considerable care to ensure that the revised version would be accepted. Reviewer comments on language infelicities can be crushing however. T1, for example, suffered what he called "an ultimate failure" when a manuscript he had edited was rejected by a prestigious journal because of language. After seven years of working as an amateur editor, this experience undermined his self-confidence:

It told me that editing manuscripts is still very hard. Even after so many years and so many successes, I still can't say my work is perfect; that I'll always be able to sweeten the gatekeepers' criticisms of language.

The fact that several professors developed very stable collaborative ties with him and 
recommended him to researchers at a university distant from NU demonstrates that authors appreciated his efforts and testifies to his success.

Although other teachers were less confident about mediating texts, and certainly found the experience challenging, no one reported complete failure. While two of the five papers T5 had edited had been accepted for publication, with the others still under review when she was interviewed for this study, she felt her current knowledge was inadequate.

There is so much to learn ...I feel I really don't know enough about the genre and only have a rough understanding of the right language. I need to look at the papers from the perspective of applied linguistics.

Similarly, although five of the six papers T6 worked on have either been accepted by conferences or local English journals, she believed those outlets had less rigorous requirements for language than prestigious Anglophone journals and her only translation of a paper for an international journal was substantially rewritten by a US coauthor. Like T5, she also stressed that she needed to learn much about academic writing to tackle the task more confidently.

The kinds of major revisions instigated by T1 and T3 might qualify them for authorship ${ }^{1}$ as now understood by many scientific journals and professional bodies. They rarely, however, pressed authors to judge whether their mediation overstepped "support" into "contributorship". $\mathrm{T} 1$, however, was added as coauthor to six papers in different disciplines while T3 to two in medicine. However, as middle authorship counts for little in the assessment of Chinese English teachers for posts or promotion, both saw this as an appreciative rather than a substantive gesture while helping authors to conform to ethical guidelines on publishing.

\section{Question 4: Factors affecting cooperation between local English teachers and authors}

\section{1) Advantages for authors}

These cases suggest that there are clear benefits to authors by having local English teachers mediate their manuscripts. Perhaps above all, such professionals are easily accessible to local

\footnotetext{
${ }^{1}$ Whether writing assistance should result in authorship qualification is contested issue (See ICMJE, 2014; Hyland, 2015).
} 
scientists as they are far more plentiful across China than native English speakers (e.g. Li \& Flowerdew, 2007). There are, in fact, over 110,000 English teachers working in Chinese universities, many of whom hold MA or PhD degrees in applied linguistics (Wang \& Han, 2011). Clearly, even if a handful of this number develops into competent text mediators then scientist authors might benefit enormously from the help they could receive.

Secondly, the fact that NNES local language professionals share the same language, culture and locality with authors may give them an edge over their NES counterparts in editing papers (Burrough-Boenisch, 2003). Not only can they communicate more effectively with each other, but they are likely to be more aware of the typical foibles and infelicities of their Chinese speaking colleagues (e.g. Burrough-Boenisch \& Matarese, 2013; He \& Gan, 2008). Ventola and Mauranen (1991), for example, show how they were able to make more successful improvements in the manuscripts of Finnish scientists than NES editors. What reviewers may see as poor language, in fact, often reflects the confusion caused by rhetorical and cultural transfer (Burrough-Boenisch \& Matarese, 2013). International NES editing services which remove the communication between editors and authors cannot provide the same support for each participant or achieve the same results and a relationship built on mutual trust and face-to-face communication (see Willey \& Tanimoto, 2013).

A third advantage for authors is that they do not need to worry that the security of their ideas may be compromised when working with local language teachers. Many editing services in China have been reported to be involved in unethical practices. Selling authorship, ghostwriting, peer review rings and even downright fraud are common (e.g. Barbash, 2015; Hvistendahl, 2013; Zhang, 2010). Both A2 and A3, for example, expressed concerns over the integrity of domestic editing services they had used and the safety of their data. Working with local language professionals, often personally known and recommended to them, they held no such fears.

Finally, but no less important, is that Chinese scientists find it far more cost-effective to engage a local language professional to mediate manuscripts. Most text mediators in this study have never charged for their services, and those that have would ask for little more than their hourly teaching rate. T1 charged only US\$32 per 1000 words, for example, or about US\$150 for 
a paper. T4 and T5 hoped they could be credited 10 to 20 teaching hours by their university for each paper they edit, equivalent to about US\$100-200. These prices, moreover, cover pre-submission mediating, follow-up revising and assistance with responding to reviewers through to the acceptance of the article. In contrast, the prices of commercial editing services can be over US $\$ 3,000$ per paper.

Accordingly, authors said they would prefer to use local teachers rather than commercial editing services, but did not know how to approach them. A2, impressed by the successful mediation service of her former English teacher, T3, for example, confessed that she is reluctant to keep asking for favors:

It is ok to ask for such a big favor from someone once, or even twice, maybe.

But it would be very embarrassing to say you want it a third time if you cannot reward her properly.

None of these authors advertised for assistance or approached teachers cold. They always solicited the recommendations of colleagues and used teachers known to their local network.

\section{2) Considerations for teachers}

Teachers reported that they felt professionally empowered by mediating texts. Like the editors reported in Harwood et al (2012) and Shashok (2001), their agentive power grew through being able to use their linguistic expertise in this way. They also benefit, like Willey \& Tanimoto's (2013) teachers, by learning from experience and consulting the EAP research literature, improving their teaching and researching skills as they develop their abilities as text mediators. Our study and conversations with teachers in China more generally suggest that many English teachers at Chinese universities have the interest and potential to become manuscript mediators for local scientists. Like English teachers in many countries, those in China often feel undervalued in the academy, playing a service role in marginalized and low-status centres on the periphery of academic activity. Many are also required to publish to advance their careers and the opportunity to mediate the texts of colleagues in the sciences offers them stimulating research. Both $\mathrm{T} 1$ and $\mathrm{T} 3$, for example, are now pursuing $\mathrm{PhD}$ degrees in this area and T5 and T6 similarly developed an interest in studying academic writing from 
their work with Chinese authors.

These advantages, however, exist in a climate of poorly organized structures for mediation and a rudimentary reward system which fails to recognize the effort of mediating papers. The fact that teacher-mediators are poorly paid was a major reason given by teachers for avoiding this work, while those who participated did so largely for reasons of altruism or professional development. T1 and T3 have been rewarded in different ways, but the others offered their time and expertise as courtesies and felt embarrassed to ask for payment. So, after successfully mediating two papers some years ago, T4 declined to develop a longer collaboration due to the excessive time involved and the lack of recognition for such work. T7 and T2 routinely decline requests from students, citing the stressful and exhausting nature of the work.

Generally I turn away translation jobs. I also find editing very taxing... so I only helped a few colleagues. For people from other universities, I won't ever offer this kind of help. As for friends, if they ask you, you have no choice [laughs].

Students often come to me well after the academic writing course I teach to ask me to edit their article manuscripts. I don't have the extra energy for that so I often introduce them to $\mathrm{T} 1$. He is good at it.

Even fee-charging text mediators like $\mathrm{T} 1$ preferred to work with only a few authors:

I don't want to advertise [my service]. To be frank, the job is very taxing and the price is not attractive at all...on average, the hourly payment is lower than $¥ 200$, even lower than teaching hours.

This lack of reward seriously undermines the development of text mediation in China.

\section{Implications: Chinese practices and possible futures}

Theoretically framed in agency and power relations, this study reveals that English teachers are an important resource for Chinese scientists seeking to publish their research in English language SCI journals. Their skills as local language professionals give them agentive power in a range of manuscript mediation activities including translation, editing and rhetorical revision, 
overcoming their unfamiliarity with specialist content and writing conventions by consulting the writing literature and regular conferencing with authors.

The fact that many mediated manuscripts found their way to publication suggests that these local language professionals enjoyed some success. We are aware that Lillis and Curry (2010) found that their European authors made very little use of local language teachers and, instead, they suggest a hierarchy of brokers with the most significant and frequent work undertaken by NES senior specialists. Indeed, they are not optimistic that language brokers are able to provide the kind of literacy support authors require:

...whether this kind of brokering alone would be sufficient to ensure publication success in other targeted publications, such as English-medium "international" journals, is questionable. (Lillis \& Curry, 2010, p.97-8)

The "academic brokers" discussed by Lillis and Curry are predominantly Anglophone-centre scholars who have academic or disciplinary expertise of various kinds. Such individuals are typically not available to most scholars working in Chinese universities, however, and local language professionals frequently perform both kinds of work, blurring the specialist-language hierarchy proposed by Lillis and Curry and perhaps loosening the hold of Anglophone centre control. The very different contexts, and the different expectations of the players in the two studies, clearly produce very different practices.

In particular, the European academics are likely to have a greater range of potential mediators to draw on, having access to co-authors and Anglophone colleagues as a result of encounters at international conferences and professional meetings, opportunities which are generally severely circumscribed for many Chinese academics. It is also possible that European scholars may regard language teachers as less competent to undertake this work. Lillis and Curry only mention two "language brokers" in their study, one a translator left entirely to her own devices by her client, and the other a school teacher who was simply asked to tidy up the grammar before submission. Not only did our local teachers spend considerable time developing a collaborative relationship with their authors to resolve problems, but most had strong academic qualifications in applied linguistics, holding higher degrees in English-related areas and being academics themselves. Such qualifications and research experience give them greater 
familiarity with the generic expectations of research writing.

Like Lillis and Curry, we see text mediation as a key activity in English-medium academic text production and, also like them, recognize that interventions in academic texts are not a neutral activity. Writing for publication always carries assumptions about the dominance of particular institutional norms and valued conventions which both authors and mediators generally seek to observe to improve the chances of acceptance. Unlike them, however, we see little inequality impacting on interpersonal collaboration and agency. We saw no evidence that the local teachers in our study exercised any hierarchical power in their relationships with authors as a result of their linguistic expertise or that the subject specialists looked down on the mediators as merely "fixer-uppers". On the contrary, these interactions were conducted with considerable respect and equality between the participants - particularly where the results are successful. Language professionals here are unsung contributors to a paper who, in addition to any direct textual intervention, often give suggestions which recognize the author's agency and expertise. They are rarely all-powerful experts calling the shots.

This study also demonstrates that the challenges created by a lack of disciplinary knowledge for English teachers when editing texts for EAL scholars can be greatly mitigated by interpersonal power, that is, close engagement with authors, supporting Willey \& Tanimoto's (2015) finding that the author's involvement is essential for text mediation success. The fact that local English teachers, using a common language with their clients and drawing on a shared cultural experience, are often in a good position to extract scientists' rhetorical intentions from otherwise awkward constructions, thus overcoming some of the difficulties experienced by Willey \& Tanimoto's (2013) NES editors. This is not to energize the tired NES vs NNES divide, but merely to state that local contexts produce affordances which may advantage one or the other.

Previous studies of text mediation in Asia (Li \& Flowerdew, 2007; Willey \& Tanimoto, 2013) and Europe (Burrough-Boenisch, 2003; Burrough-Boenisch \& Matarese, 2013) underline the importance of text mediation support for authors and for the professionalization of EAP teachers. We are aware that many EAP teachers are likely to be dismayed by our findings and to view the kind of semi-amateur, ad hoc and informal status which text mediating practices have in China to 
be far from the desirable professionalized and respected role it has in many other countries. While we acknowledge that the authors gain massive benefits from this service and English teachers enjoy what might be regarded as important insights into academic writing and valuable professional development, we are merely seeking to describe a transitional stage in China's evolving participation in the global publication system and not, of course, celebrating this model or promoting it to others.

As a small-scale study our research offers scope for improvement and development. The fact that we have looked at only eight English teachers and four scientific authors means that its generalizability remains limited, suggesting the possibility of further research with other populations in other universities. Furthermore, while the scarcity of NESs in Chinese universities and the restrictions imposed on the kinds of work they can engage in mean they are not available to many Chinese academics, their role as mediators in China cannot be ruled out entirely. Future research may explore a larger sample size which might include NES English teachers.

Finally, it is worth pointing out that the unofficial, informal relationship between local English teachers and scientist authors we have described is certainly not ideal. In fact it may seem to undermine the professionalism of EAP practitioners and hinder the progress of more structured institutional recognition. There are certainly cultural factors involved in authors' hesitancy in approaching teachers as professional text mediators and in teachers' reluctance to ask for reward for their efforts. Participants clearly found it difficult to transform personal connections into commercial relationships. More importantly, however, we can see English for research publication purposes in China is in a transitional stage where English language publishing is growing rapidly while the field is not yet sufficiently mature to permit a more formal, institutionalized response to the issue of faculty writing support.

Teachers at the university language centres, like the one at PU, are clearly working hard to raise the academic credibility and standing of their profession and the value of their work, but such initiatives in China require high-level university sponsorship. Only by demonstrating the advantages of this writing support in boosting the international visibility, ranking and reputation of their academics will senior administrators begin to take this work seriously and deem it worthy of the financial and professional assistance that scientists sorely need and teachers fully deserve. 


\section{References}

Archer, M. (1995). Realist Social Theory: The Morphogenetic Approach. Cambridge, UK: CUP.

Barbash, F. (2015, March 27). Major publisher retracts 43 scientific papers amid wider fake peer-review scandal. Retrieved from https:/www.washingtonpost.com/

Belcher, D. (2007). Seeking Acceptance in an English-Only Research World. 13(1), 23-34. Journal of Second Language Writing, 16 (1) 1-22.

Benfield, J. R., \& Feak, C. B. (2006). How authors can cope with the burden of English as an International language. CHEST, 129, 1728-1730.

Burrough-Boenisch, J. (2003). Shapers of published NNS research articles. Journal of Second Language Writing, 12, 223-243.

Burrough-Boenisch, J. (2013). Defining and describing editing. In V. Matarese (Ed.), Supporting research writing: Roles and challenges in multilingual settings (pp. 141-156). Oxford: Chandos Publishing.

Burrough-Boenisch, J., \& Matarese, V. (2013). The authors' editor: Working with authors to make drafts fit for purpose. In V. Matarese (Ed.), Supporting research writing: Roles and challenges in multilingual settings (pp. 173-190). Oxford: Chandos Publishing.

Canagarajah, S. (2012). Teacher development in a global profession: An autoethnography. TESOL Quarterly, 46, 258-279

Cargill, M., O’Connor, P., \& Li, Y. (2012). Educating Chinese scientists to write for international journals: Addressing the divide between science and technology education and English language teaching. English for Specific purposes, 31(1), 60-69.

Coniam, D. (2012). Exploring reviewer reactions to papers submitted to academic journals. System, 40, 544-553.

Davies, A. (2003). The Native Speaker: Myth and Reality. Clevedon: Multilingual Matters.Ehara, S. \& Takahashi, K. (2007). Reason for rejection of manuscripts submitted to AJR by international authors. AJR, 188, W113-W116.

Flowerdew, J. \& Li, Y-Y. (2007). Language re-use among Chinese apprentice scientists writing for publication. Applied Linguistics, 28(3), 440-465. 
Fu, J., Frietsch, R. \& Tagscherer, U. (2013). Publication activity in the Science Citation Index Expanded (SCIE) database in the context of Chinese science and technology policy from 1977 to 2012. Retrieved from http://hdl.handle.net/10419/80446

Giddens, A. (1984). The Constitution of Society: Outline of the Theory of Structuration. Cambridge, UK: Polity Press

Gosden, H. (1992). Research writing and NNSs: From the editors. Journal of Second Language Writing, 1(2), 123-139.

Gosden, H. (1995). Success in research article writing and revision: A social-constructionist perspective. English for Specific Purposes. 14(1), 37-57Harwood, N., Austin, L., \& Macaulay, R. (2009). Proofreading in a UK university: Proofreaders' beliefs, practices, and experiences. Journal of Second Language Writing, 18(3), 166-190.

Harwood, N., Austin, L., \& Macaulay, R. (2012). Cleaner, helper, teacher? The role of proofreaders of student writing. Studies in Higher Education, 37(5), 569-584.

He, H., \& Gan, K.-J. (2008). Advantages of English-fluent Chinese editors over native-English-speaking editors in editing Chinese biomedical manuscripts. Science Editor, 31, 189-192.

Hyland, K. (2015). Academic publishing: Issues and challenges in the construction of knowledge. Oxford: OUP.

Hyland, K. (2016). Academic publishing and the myth of linguistic injustice. Journal of Second Language Writing, 31(1), 58-69

Hvistendahl, M. (2013). China's publication bazaar. Science, 342(6162), 1035-1039.

Institute of Scientific and Technical Information of China (ISTIC). (2015). Statistical data of Chinese S \& T papers. Retrieved from http://www.istic.ac.cn

International Committee of Medical Journal Editors (ICMJE). (2014). Recommendations for the conduct, reporting, editing, and publication of scholarly work in medical journals. http://www.icmje.org

Kerans, M. E. (2001). Eliciting substantive revision of manuscripts for peer review through process-oriented conferences with Spanish scientists. In C. Munoz (Ed.) Trabjos en linguistica aplicada (pp. 339-347). Barcelona: Universitat de Barcelona. 
Könner, A. (1994). Bioscript—an editorial service for scientists. English Today, 10 (2), 44-48.

Kyburz, B. L. (2004). Meaning finds a way: Chaos (theory) and composition. College English, 66(5), 503-523.

Layder, D. (2006). Understanding Social Theory (2 ${ }^{\text {nd }}$ Edition). London: SAGE

Li, Y., \& Flowerdew, J. (2007). Shaping Chinese novice scientists' manuscripts for publication. Journal of Second Language Writing, 16(2), 100-117.

Lillis, T., \& Curry, M. J. (2010). Academic Writing in a Global Context: The Politics and Practices of Publishing in English. NY: Routledge.

Mungra, P., \& Webber, P. (2010). Peer review process in medical research publications: Language and content comments. English for Specific Purposes, 29(1), 43-53.

Mur Dueñas, P. (2012). Getting research published internationally in English: An ethnographic account of a team of Finance Spanish scholars' struggles. Ibérica 24: $139-156$.

Prior, P. (1998).Writing/disciplinarity: A sociohistoric account of literate activity in the academy. Mahwah, NJ: Erlbaum.Saldaña, J. (2009). The coding manual for qualitative researchers. Thousand Oaks, CA: SAGE

SCImago (2014). Journal and country rank. SCImago. Retrieved from http://www.scimagojr.com/country rank.php.

Shashok, K. (2001). Author's editors: Facilitators of science information transfer. Learned Publishing, 14, 113-121.

Shashok, K. (2014). My life as an editor. European Science Editor, 40(1), 21.

Sionis, C. (1995). Communication strategies in the writing of scientific research articles by non-native users of English. English for Specific Purposes, 14 (2): 99-113.

Ventola, E., \& Mauranen, A. (1991). Non-native writing and native revising of scientific articles. In E. Ventola (Ed.), Functional and systemic linguistics: Approaches and uses (pp. 457-492). Berlin: Mouton de Gruyter.

Wang, X., \& Han, J. (2011). On the present conditions and development bottleneck of foreign language teachers' academic research in Chinese institutions of higher learning from an empirical perspective. Journal of the Foreign Language World, 24(3), 44-51. 
Willey, I., \& Tanimoto, K. (2012). “Convenience Editing” in action: Comparing English teachers' and medical professionals' revisions of a medical abstract. English for Specific purposes, 31, 249-260.

Willey, I., \& Tanimoto, K. (2013). "Convenience editors" as legitimate participants in the practice of scientific editing: An interview study. Journal of English for Academic Purposes, 12, 23-32.

Willey, I., \& Tanimoto, K. (2015). "We're drifting into strange territory here": What think-aloud protocols reveal about convenience editing. Journal of Second Language Writing, 27, $63-83$

Zhang, Y. (2010). Chinese journal finds 31\% of submissions plagiarized. Nature, 467, 153.

Appendix 1 Interview schedule

1. How often have you been requested by authors from other disciplines to help with their English manuscripts?

2. How many of these papers have you mediated?

3. To which disciplines do they belong?

4. Why do you think these authors turn to you for help?

5. Do you know anything about the submission process and journals of the manuscripts you mediated? If yes, please describe.

6. How do you decide which papers to work on and which to decline?

7. Can you describe what you do when receiving a paper?

8. How many times do you work on the same manuscript?

9. What are the main challenges in doing this work? How do you deal with these?

10. Do you communicate with the author when mediating the paper? If yes, at what stages and why?

11. In addition to text editing, do you help the author(s) with the submission process? If yes, in what ways?

12. What do you think you contribute to the publishing success of the authors you work with?

13. How do you benefit personally from doing this work? 14. Are there other effects your service might have on the author(s) writing or publishing? 
15. What rewards or benefits do you receive for this work?

16. Does the text mediation affect you in any way? If yes, how?

Appendix 2 Draft coding heuristic

\begin{tabular}{ll}
\hline Change scales & Definitions and examples from participants' revisions \\
\hline Minor changes & Addition, deletion, substitution and reordering of grammatical \\
& markers, words, and phrases \\
& Example: When the coiling temperature rose (minor \\
& addition) to $700{ }^{\circ} \mathrm{C}$, the microstructure are still remains \\
& to be (minor substitution) ferrite-pearlite,-as shown in \\
& Figure $4 \cdots$ as shown in Fig. 4. (minor reordering) [LET5]
\end{tabular}

Meso changes

Addition, deletion, rewriting and reordering of clauses and sentences combination and splitting of sentences.

Example: Atherosclerosis plaque $\cdots$ is closely related to the activation of PPARy, which It is known that PPARy and RXR form a heterodimer that promotes facilitates (meso rewriting) the expression of multiple transporters, including ABCA1, ABCG1, SR-B1, CD36, apoE, and LXR. Furthermore, the activation of PPARy is essential for the regulation of macrophage function in atherosclerosisplaque formation. (meso deletion) [LET3] 


Major changes
continuous sentences, reorganization of subsections and sections.
Example: Because the area of the grounding grid is usually large, the
power of the current sources injected into the grounding grid would
be much larger. Since it is difficult to manufacture such a large
eurrent source of varying frequencies, two current sources are-
injected into the grounding grid. If the frequency is too low... (major
deletion) [LET1]

